\title{
التخطيط والتنمية الاقتصادية
}

\section{Planning and economic development}

Rania Alzahrani رانيا الزهراني

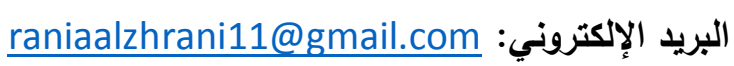

يُعد النظام الاقتصادي القوي أحد أهم الدعائم في نهضة الأمم والثعوب، لتحقيق التتمية الاقتصادية وتأمين حياة كريمة لأفراد المجتمع، من خلال توفير البنى العمرانية والتعليمية والصحية، كتوفير المدارس والجامعات، ورفع مستوى هذه المؤسسات، وتأهيل الكوادر الطبية في المؤسسات الصحية، وتأمين الأجهزة الطبية ذات الجودة العالية، وفرص العمل، وتحقيق الاكتفاء الذاتي من منتجات زراعية وصناعية وتتويع مصادر الدخل بتتشيط القطاعات الاقتصادية المختلفة، بدلاً من الاعتماد على مصدر واحد فقط. وبذللك تتعزز قدرة الدول التي تتمتع باقتصاد قوي على مواجهة الأزمات الاقتصادية والاجتماعية التي قد تسبب بدورها خلاً في بنية وتماسك الأنظمة الاجتماعية والاقتصادية. ولكي يكون النظام الاقتصادي جيداً وقوياً، لا بد من وجود ظروف وعوامل مساعدة، طبيعية وبشرية وإدارية، أهمها التخطيط الاقتصادي المبني على خطط ومبادئ علمية مدروسة ودقيقة. وقد بدأت الخطط الاقتصادية طويلة المدى بالظهور في الدول الاشتراكية عام 1928 عندما وضع الاتحاد السوفيتي أول خطة خُمسية آنذاك، ثم تزايد الاهتمام بالتخطيط الاقتصادي بعد الحرب العالمية الثانية، حيث أولت الدول اهتماماً كبيراً بالتخطيط والبرامج الاقتصادية لتأمين مستوى معيثي جيد وحياة أفضل لمجتمعاتها وأفرادها (1). ويُعرف التخطيط بشكل عام "بأنه نشاط مُنظم يهدف إلى تتمية وترشيد ودعم استقرار الاقتصاد من خلال تحديد مجموعة واقعية من الأهداف والأولويات الاقتصادية والاجتماعية، المتتاسقة مع المستوى المحلي والقومي والإقليمي، وتعيين الأساليب الفنية والوسائل اللازمة التي تساعد على تحقيق تلك الأهداف، وتتفيذ الخطط المرسومة. أي، إن التخطيط الاقتصادي هو نشاط عمدي يهدف إلى إحداث تقدم مقصود لالاقتصاد (2)

وتقوم عملية التخطيط الاقتصادي الجيد على عدد من الخصائص والثروط (3)، أهمها: 1) الواقعية: حيث ينبغي أن تتلاءم أهداف الخطط الاقتصادية وغاياتها مع معطيات الحالة السائدة

$$
\text { وإمكانية التنفيذ في ضوء الإمكانيات المتاحة. }
$$

2) الوضوح: ينبغي أن تكون الخطة الاقتصادية واضحة المعالم والأهداف، لا غموض فيها ولا لبس. 
3) الاستمرارية: عدم التوقف عن التتفيذ والتخطيط المتواصل. 4) تحديد الأولويات والبدائل: الخطة الناجحة هي التي ترتب أولوياتها وتضع البدائل في حال الفشل. 5) التوقع أو التتبؤ استعداداً لأي طارئ اقتصادي، اعتماداً على استشراف المستقبل والمعطيات المستتدة على المعلومات المتوفرة وأحدث الأساليب التقنية والفنية في الإدارة والاقتصاد. 6) تحديد مسؤوليات التنفيذ بصورة دقيقة، بما ينسجم مع قدرات الجهات المنفذة (3). ويتفرع عن التخطيط الاقتصادي عدة أهداف، منها:

أهداف اقتصادية تتعلق بالكفاءة الإنتاجية، أي تحقيق أقصى ما يمكن من المنافع المادية، ومن هذه الأهداف: 1) زيادة الدخل الحقيقي للفرد عن طريق زيادة مستوى الإنتاج من السلع والخدمات، 2) زيادة مستوى استخدام قوة العمل وتوفير العمل لكافة الأفراد القادرين عليه، 3) تطوير هيكل البناء الاقتصادي وتتويع الإنتاج، 4) تطوير خبرات ومهارات الموارد البشرية. أهداف اجتماعية تتعلق بالعدالة، وتكافؤ الفرص في التعليم والصحة، التي تعد من أهم مفاتيح التطوير النوعي لمدارك الإنسان، وأهمها: 1) تقليل التفاوت في توزيع الدخل، 2) توسيع نطاق التعليم والعمل على رفع مستواه، 3) تحسين الأوضاع الصحية وقائياً وعلاجياً، 4) تطوير وسائل التقافة والمقومات الفكرية والحضارية (1).

ويمكن هنا تسليط الضوء على مثال واقعي من التخطيط الاقتصادي في المملكة العربية السعودية، وهو "رؤية 2030" (4)، التي تهدف إلى تتمية الاقتصاد وتتويع مصادره وتتمية المجتمع، وذلك من خلال ثثلاثة محاور، هي: المجتمع الحيوي، والاقتصاد المزدهر، والوطن الطموح، حيث تتكامل هذه المحاور ويتّسق بعضها مع بعض في سبيل تحقيق الأهداف وتعظيم الاستفادة من مرتكزات الروئة، التي تبدأ من

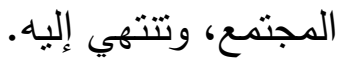

ويمثّل المحور الأول أساساً متيناً لتحقيق هذه الرؤية لتأسيس قاعدة صلبة للازدهار الاقتصادي، منبثقاً من الإيمان بأهمية بناء مجتمع حيوي، يعيش أفراده وفق المبادئ الإسلامية ومنهج الوسطية والاعتدال، معتزين بهويتهم الوطنية وفخورين بارثهم الثقافي العريق، في بيئة إيجابية وجاذبة، تتوافر فيها مقوّمات جودة الحياة للمواطنين والمقيمين، ويسندهم بنيان أسري منتي، ومنظومة رعاية صحية واجتماعية قوية. ويرتكز المحور الثاني على الاقتصاد المزدهر، من خلال توفير الفرص للجميع، عبر منظومة تعليمية مرتبطة باحتياجات سوق العمل، وتتمية تلك الفرص لروّاد الأعمال والمنشآت الصغيرة والشركات الكبيرة، وتطوير الأدوات الاستثمارية، لإطلاق إمكانات القطاعات الاقتصادية الواعدة وتتويع الاقتصاد وتوليد فرص العمل للمواطنين. ولإيمان بدور التنافية في رفع جودة الخدمات والتتمية الاقتصادية، تركزّ 
الجهود على تخصيص الخدمات الحكومية، وتحسين بيئة الأعمال، بما يُسهم في استقطاب أفضل

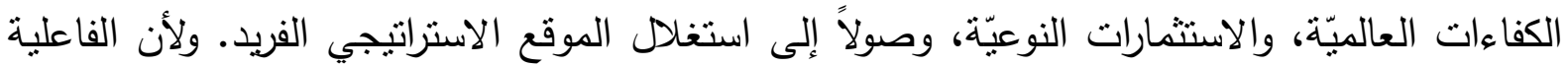

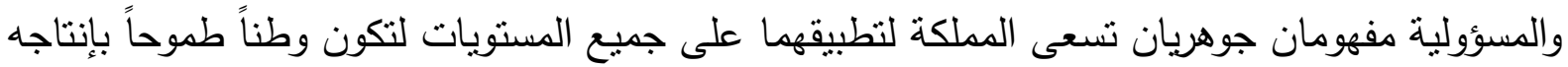
ومنجزاته، لذللك، تركز الروئة في المحور الثالث على القطاع العام، حيث ترسم ملامتح الحكومة الفاعلة من خلال تعزيز الكفاءة والثفافية والمساءلة وتتجيع نقافة الأداء لتمكين الموارد والطاقات البشرية، وتهيئ البيئة اللازمة للمواطنين وقطاع الأعمال والقطاع غير الربحي لتحمل المسؤوليات، وأخذ زمام المبادرة في مواجهة التحديّات وإيجاد الفرص الاستثمارية (ل).

ومن الجدير بالذكر أن عملية التخطيط للتتمية الاقتصادية ترتبط بشكل مباشر بسياسة الدولة، فمن غير الممكن تحقيق تتمية اقتصادية والتخطيط لها، إذا لم تكن الدولة قادرة على سن القوانين المناسبة التي

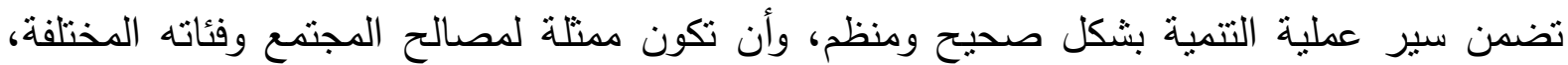

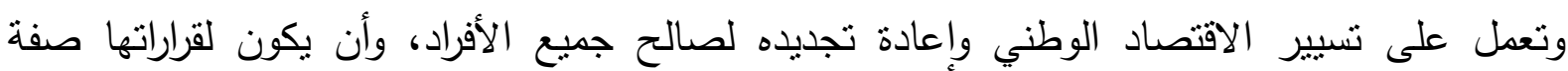
الإلزامية النهائية على كافة الصعد. أي أن تتخذ السلطة القرارات الاقتصادية والاجتماعية المهية،

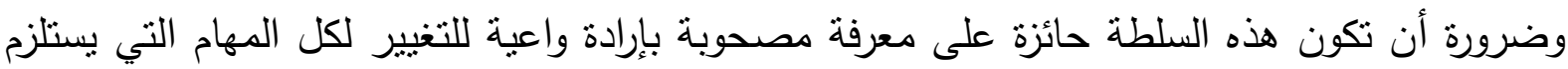
وجودها التقام الاقتصادي والاجتماعي، ومُلمة بالأساليب والأدوات اللازمة للتخطيط الثنامل (5).

وأخيراً، يمكن القول إن دفع عجلة التقام والتتمية الاقتصادية يحتاج إلى تظافر الجهود على مختلف المستويات، في ظل وجود سياسة اقتصادية واضحة المعالم، تُخطط وتُثف وتستشرفُ احتباجات أفراد المجتمع، لتحقيق التتمية المتوخًاة. ومن خلال الاستثمار المتواصل في الإنسان والمجتمع، يمكن بناء

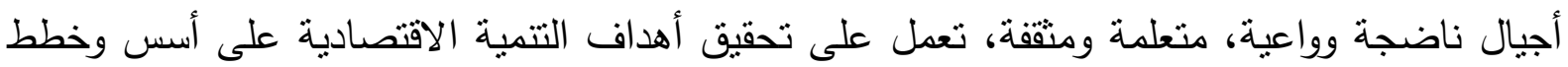
علمية منظمة ومدروسة بشكل دقيق.

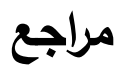

1) سلمان، جمال داؤد و حسون، طاهر فاضل (1989): التخطيط الاقتصادي، بيت الحكمة، جامعة بغداد، العراق. 2) المقصود، سيد (2018): أسس ومبادئ التخطيط الاقتصادي الإقليمي والعمراني، دار حسان، مصر . 3) الكرخي، مجيد (2014): التخطيط الاستراتيجي المبني على النتائج، دار الغشام، قطر.

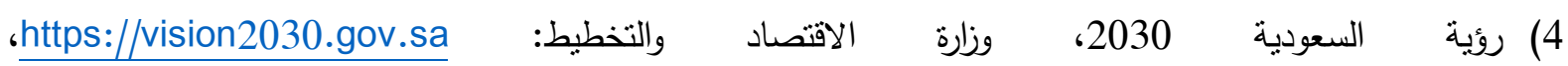
20 2020 iاريخ الاطلاع: 28 نوفمبر 5) مسعود، مجيد (1404): التخطيط للتقدم الاقتصادي والاجتماعي، عالم المعرفة، الكويت. 